\title{
Optimal application of conceptual rainfall-runoff hydrological models in the Jinshajiang River basin, China
}

\author{
MUHAMMAD TAYYAB, JIANZHONG ZHOU, XIAOFAN ZENG, LU CHEN \& \\ LEI YE \\ School of Hydropower \& Information Engineering, Huazhong University of Science \& Technology, Wuhan, China \\ muhammadtayyab018@gmail.com
}

\begin{abstract}
For specific research areas different hydrological models have shown different characteristics. By comparing different hydrological models on the same area we should get better and more authentic results. The objective of this research study is to highlight the importance of model selection for specific research areas. For the Jinshajiang River basin, three conceptual hydrological models including the Xin'anjiang model, the Antecedent precipitation index (API) model and the Tank model are applied to select the most suitable model for flood forecasting, based on the hourly rainfall and hourly discharge data. Data were analysed by comparing the simulation outputs of the three models with the Nash-Sutcliffe efficiency and Correlation coefficient index. Results showed that the performance of the three models were not very different. On the basis of data need and the characteristics of the research basin, the Xin'anjiang model was selected as the optimal and practical conceptual hydrological model for the Jinshajiang River basin.
\end{abstract}

Key words flooding forecast; Xin'anjiang model; Antecedent precipitation index (API) model; Tank model; Jinshajiang River basin

\section{INTRODUCTION}

Generally, floods are considered as the most dangerous natural hazards after storms and earthquakes. The frequency of floods has increased in the last few decades due to the effect of global warming (IPCC). There is also a theoretical expectation that climate warming will result in increases in evaporation and precipitation leading to the hypothesis that one of the major consequences will be an intensification (or acceleration) of the water cycle. This intensification results in heavy rains and, due to climate warming, it also affects the rate of melting glaciers, which causes the floods. Complete safety from flooding is not possible, but huge amounts of money and countless lives can be saved by timely and accurate predictions of flood crests, flood magnitude and flood duration. Different investigators have used different techniques, methods and models to investigate floods. In the last 30 years, many advances have been achieved by different researchers with numerous distributed hydrological models for rainfall-runoff simulations. Most of the spatially-distributed physically-based models, such as KINEROS (Smith et al. 1995), SHE (Abbott et al. 1986), TOPKAPI model (Todini and Ciarapica 2001; Liu et al. 2005), consider land use, soil information, water balance at a highly detailed spatial and temporal resolution. However, these models can explain the different problems at different levels, but their application is limited because of their complex structures and requirements for huge amounts of data with numerous parameters. In contrast to distributed physically-based models, the conceptual distributed or semi-distributed hydrological models, are simple in terms of structure, and requirements for data and the parameters. Such models include TOPMODEL (Beven and Kirkby 1979), the HBV model (Bergström1976), Xinanjiang model (Zhao et al. 1980) and ARNO model (Todini 1996). Now, the focus is to develop such conceptual model which include the merits of the conceptual rainfall-runoff models and overcome the deficiencies of physically-based models (Robinson and Sivapalan 1995; Koren et al. 2003; Chen et al. 2007; Yao et al. 2009; Zhang and Werner 2009). Some research has shown that the conceptual distributed hydrological models are applicable in the field of flood forecasting (Chen et al. 2007; Yao et al. 2009). In this study, to forecast floods with high precision efficiency, three kinds of conceptual distributed hydrological models are applied to construct rainfall-runoff process. 


\section{DATA AND STUDY AREA}

The Yangtze is the largest river in china and considered as the third largest river in the world. The mainstream length of the Yangtze River is about $6380 \mathrm{~km}$, basin area is more than $1.81 \times 106 \mathrm{~km}^{2}$ and annual average discharge into the East China Sea is more than $9.79 \times 10^{11} \mathrm{~m}^{3}$. Yangtze River has been divided into three parts, upper, middle and lower Yangtze River basin. The upper and lower Yangtze basin contain several important tributaries but the lower reaches are characterized by a number of lakes. The upper reach of Yangtze River is known as Jinshajiang River (Fig. 1), which originates from the Qinghai-Tibet plateau. Jinshajiang River flows through five major landforms: the Qinghai-Tibet plateau, the western Sichuan plateau, the Hengduan Mountains, the Yunnan-Guizhou plateau and the mountainous area of SW Sichuan. The Jinshajiang basin drains an area of $4.7 \times 10^{5} \mathrm{~km}^{2}$, its areal extent is about $3400 \mathrm{~km}$ and the annual runoff volume is $1.52 \times$ $10^{10} \mathrm{~m}^{3}$. Topographically and chemically this region has much complexity. The northwest part of this basin is more elevated than the southwest. Due to complicated geographical conditions this basin has many types of climate pattern, including typical plateau climate, the Hengduan Mountains, Vertical climate and a monsoon climate. The simulated river channel in this study is from Panzhihua section to Xiangjiaba section, and the forecast station is Xiangjiaba station. Between these are located Xiangjiaba hydropower station, Fushui (right bank) and Sichuan Yibin County (left bank) within the Jinsha River, and Xiluodu hydropower dam $157 \mathrm{~km}$ away. The dam controls a drainage area of $458800 \mathrm{~km}^{2}$, accounting for $97 \%$ of the Jishajiang River basin area; the average annual runoff of $3810 \mathrm{~m}^{3} / \mathrm{s}$.

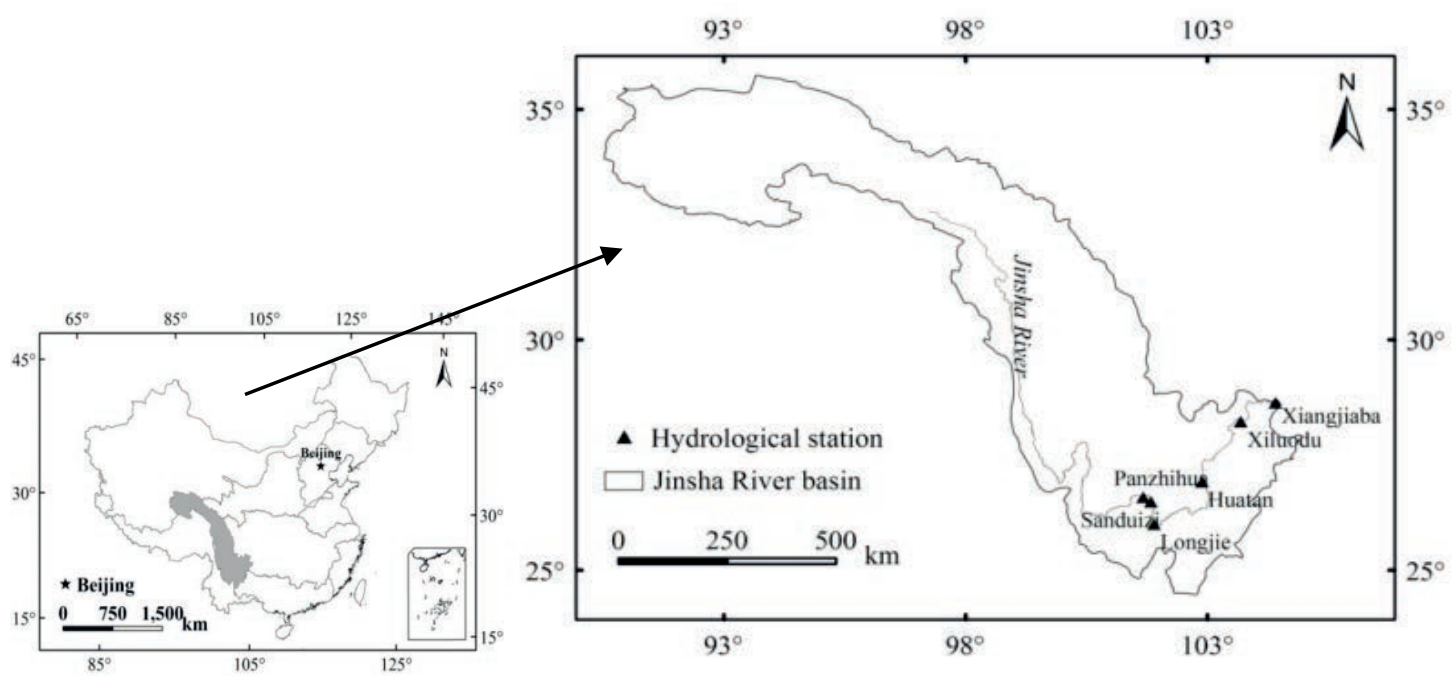

Fig. 1 Location of the Jinshajiang River basin and some hydrological stations

To predict the discharge of the Jinshajiang river basin at the Xiangjiaba gauging station, rainfall and runoff data at seven gauging stations in the mainstream including Panzhihua, Sanduizi, Longjie, Wudongde, Huatan, Baihetan and Xiluodu, for 2004-2013 were used. The data availability is in every one hour, in other words the forecast lead time is one hour. Along the main streams some tributaries also generate runoff into the main stream. Figure 2 shows the location of tributaries to the main stream. 


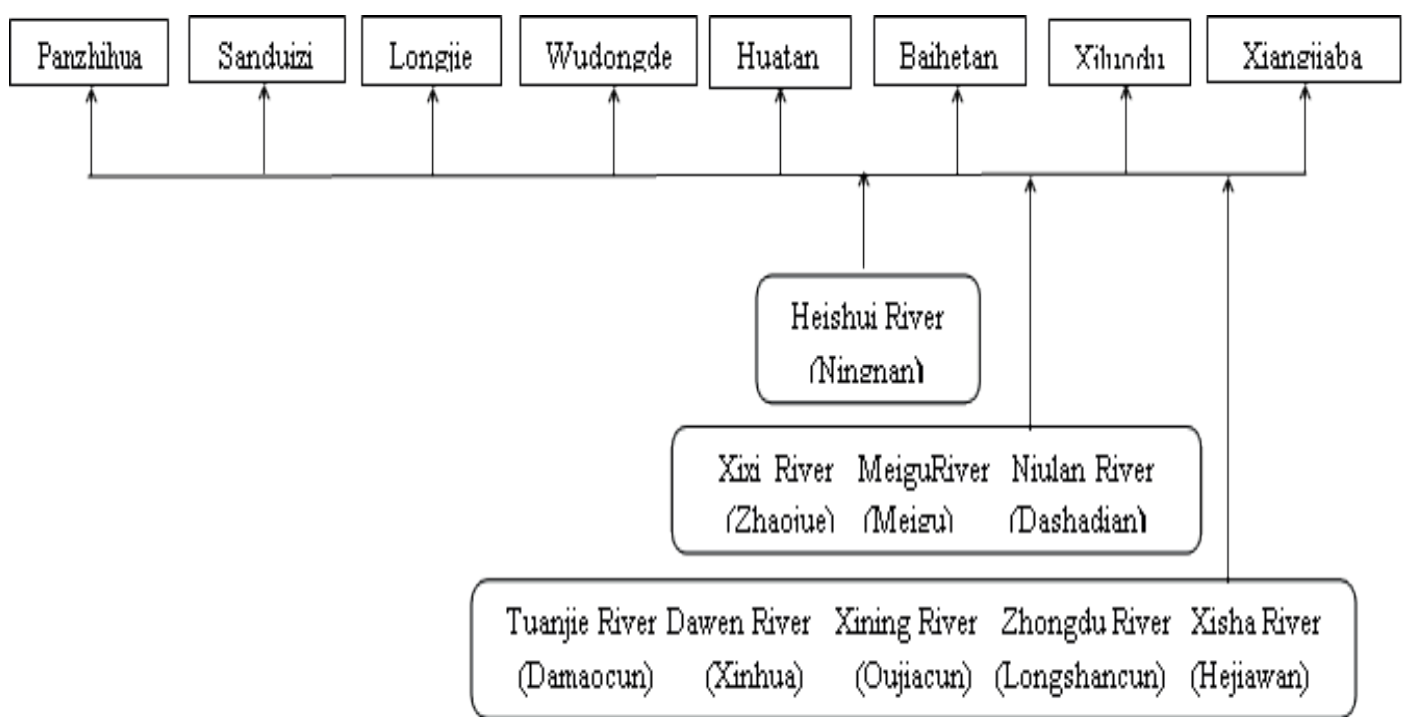

Fig. 2 Location of tributaries to the main stream.

\section{DESCRIPTION OF MODELS}

The present study is about obtaining the best results among the three hydrological models (the Xin'anjiang, Antecedent precipitation index (API) and Tank models); the literature shows much advancement and improvement in this field as well. Since the 1970s, the Xin'anjiang model development has shown many application results for humid and semi-humid regions in China (Zhao, 1977, 1984; Todini, 1996; Zhao et al., 1980). Xin'anjiang model delivers an important arrangement to describe non-uniform runoff producing areas statistically. A single parabolic curve in this model shows the spatial distribution of soil moisture storage capacity over the catchment, while exponent parameters provide non-uniformity of this distribution. API was first presented by Kohler (Kohler and Linsley 1950) at a time when it was difficult to understand soil properties using infiltration theory, especially in large basins (Benkhaled et al. 2004). The API has been used to estimate soil moisture (Sittner et al. 1969), the consumption by surface and groundwater runoff, and also evaporation consumption (Wei et al. 2005). Based on the API model, a simplified equation was introduced to predict the soil relative moisture (SRM) in areas lacking monitoring data (Zhao et al. 2011). Among all the other rainfall-runoff models, the Tank model is most popular in Japan. It was firstly proposed by Sugawara in the 1950s but its application spread later in other regions (Jaywerdena 1988), when the associated literature was disseminated in English (Sugawara et al. 1984). The Tank model is a continuous, lumped, deterministic, non-linear and time-invariant model, that transforms the measured precipitation or rainfall into a corresponding runoff without having to estimate losses and base flows separately. The method used to predict the disturbance in the shape of water in the process of moving through a river channel is known as Routing. Many researchers have used flow routing models (Fread, 1985; Liggett and Cunge, 1975; Linsley et al. 1986) and believe they get appropriate results by applying limitations. The famous hydrologic (lumped) flow routing method named the Muskingum Method was introduced by McCarthy (1938). The Muskingum Method provides a substitute for the routing hydrograph through stream reaches, which is well constructed by researchers (McCarthy, 1938; Pone and Yerjevich 1978; Pone and Theurer 1982; Perumal 2008; Tang et al. 1999; Birkhead, 2002; AlHumond and Esen, 2006). Simple requirement for applying this method makes it more attractive to researches in practical use. Besides giving some unrealistic results by this method, it also has shown characteristic to provide suitable results for mediate and low level floods (Maidment and Fread 1993). 


\section{CALIBRATION AND VERIFICATION}

For calibration and verification of the three hydrological models (Xin'anjiang, API and Tank model), we selected two sub-basins, Niulan River basin and Xining River basin, having areas of $12977 \mathrm{~km}^{2}$ and $971 \mathrm{~km}^{2}$, respectively. There were 13 years (2000-2012) of continuous daily stream flow recorded for Niulan sub-basin; the initial 6 years (2000-2006) of data were used for calibration and later 6 years (2007-2012) for verification purposes. For Xining River basin, continuously daily stream flow was recorded for 8 years (2006-2013); for calibration we used the initial 5 years (2006-2010) of data, and the last 3 years (2011-2013) were used for verification. The characteristics and efficiencies of these three models were calculated at both sub-basins by using the Nash-Sutcliffe efficiency. Calculated values for each sub-basin by each model through the Nash-Sutcliffe efficiency index are shown in Table 1. Parameters for each model were fixed by reference to the literature (Zhao 1992) or adjusted using trial and error.

Table 1 Model performance in the Niulan and Xining River basins.

\begin{tabular}{lllllll}
\hline Sub-basin & Niulan River basin & \multicolumn{5}{l}{ Xining River basin } \\
\hline Model & Xin'anjiang & API & Tank & Xin'anjiang & API & Tank \\
Calibration & 0.86 & 0.65 & 0.74 & 0.80 & 0.77 & 0.61 \\
Verification & 0.75 & 0.70 & 0.58 & 0.76 & 0.76 & 0.66 \\
\hline
\end{tabular}

\section{RESULTS}

After calibration and verification of the three hydrological models (Xin'anjiang, API, Tank), two typical flood events were selected from Xiangjiaba station. The two typical flood events started on 2013-07-18 and 2013-08-14 respectively. Our results demonstrate a suitable correlation between observed and simulated hourly discharge in both flood events for all three models. To evaluate the results, the simulation outputs were compared using the Nash-Sutcliffe efficiency and correlation coefficient index. Their performance and efficiency for two typical flood events is shown in Table 2.

Table 2 Models performances for selected flood events

\begin{tabular}{llll}
\hline Flood event & Models & Nash-Sutcliffe efficiency & Correlation coefficient \\
\hline $2013-07-18$ & Xin'anjiang & 0.84 & 0.98 \\
& API & 0.59 & 0.98 \\
& Tank & 0.63 & 0.98 \\
$2013-08-14$ & Xin'anjiang & 0.86 & 0.98 \\
& API & 0.77 & 0.94 \\
& Tank & 0.70 & 0.97 \\
\hline
\end{tabular}

The Nash-Sutcliffe efficiency and correlation coefficient index results show that the Xin'anjiang model is the best performer and the flow hydrograph supports the results of both indices. By comparing flow hydrographs by the three models of flood event 2013-07-18, we can conclude some results. For API, the flow hydrograph has more irregular results compared to the two other models, especially in the earlier and later stages, the peaks show unsatisfactory results. The Tank model flow hydrograph has better results compared to API but still no consistency and satisfactory results. However, throughout the Xin'anjiang model flow hydrograph shows more valuable, consistent and satisfactory results than either the API or Tank models (Fig. 3).

Starting from the flow hydrograph of the API model for 2013-08-14, we can see a huge difference between the observed and simulated values in the start; in middle section it has better results but overall it is not satisfactory. The Tank model flow hydrograph shows a specific consistency as compared to API; there are no extreme peaks in the Tank model flow hydrograph so it is easy to understand the behaviour in this section as compared to API. For Xin'anjiang model flow hydrograph, we can easily say that it is more effective model for predicting the exact values in this section; from start to end it has consistency and desirable accuracy (Fig. 4). 

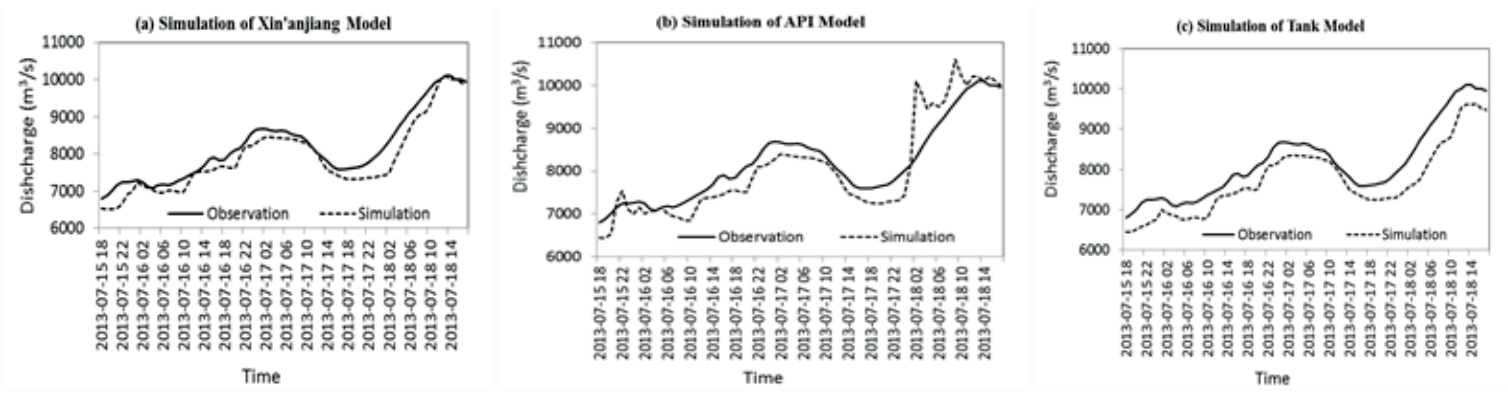

Fig. 3 Simulation flow hydrograph of flood event 2013-07-18. Simulations by: (a) Xin'anjiang, (b) API and (c) the Tank model.
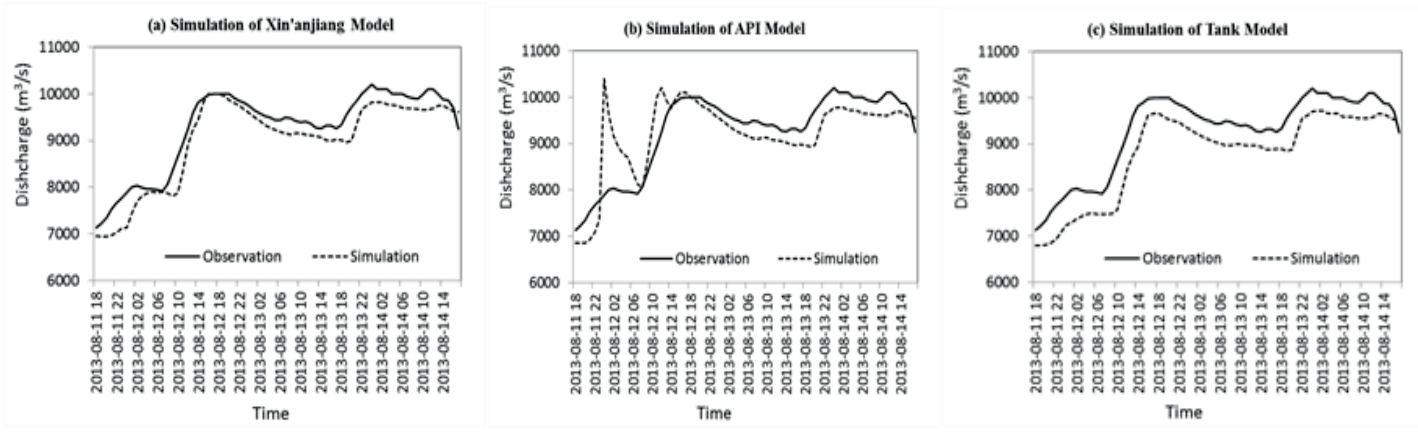

Fig. 4 Simulation flow hydrograph of flood event 2013-08-14. Simulations by: (a) Xin'anjiang, (b) simulation of API model (c) Simulation of Tank model.

\section{CONCLUSION}

To select the consistent and suitable hydrological model for Jinshajiang River basin, three hydrological models were applied for two selected flood events at Xiangjiaba station. In general, each model has shown satisfactory results, but the Xin'anjiang model showed more consistent, suitable and accurate results. Comparing the two indices (Nash-Sutcliffe efficiency and correlation coefficient) and flow hydrographs of the three models, the results show that Xin'anjiang model is more reliable and applicable for the research area. Due to the data needs and the characteristics of the research basin, the Xin'anjiang model was selected as the optimal and practical conceptual hydrological model for the Jinshajiang River basin.

Acknowledgement This work is supported by the State Key Program of National Natural Science of China (No. 51239004) and the National Natural Science Foundation of China (No. 51309105). I really appreciate my supervisor Professor Jianzhong Zhou and other colleagues, that they have helped me to complete this work. Special thanks to anonymous editors and reviewers for their constructive comments.

\section{REFERENCES}

Beven, K.J. and Kirkby, M.J. (1979) A physically based variable contributing area model of basin hydrology. Hydrological Sciences Journal, 24(1). 43-69.

Abbott, M.B., et al. (1986) An introduction to the European Hydrological System-Systeme Hydrologique European, "SHE", 2, Structure of a physically-based, distributed modeling system. Journal of Hydrology, 87. 61-77.

Al-Humoud, J. M. and Esen, I. I. (2006) Approximate methods for the estimation of Muskingum flood routing parameters. Water Resources Management 20(6), 979-990.

Benkhaled, A. et al. (2004) Influence of antecedent precipitation index on hydrograph shape. In: Hydrology: Science and practice for the 21 st century. Proceedings of the British Hydrological Society International Conference, Imperial College, London. 81-87

Bergström, S. (1976) Development and application of a conceptual runoff model for Scandinavian catchments. Department of Water Resources Engineering, Lund Institute of Technology, Bulletin Series A-52, Swedish Meteorological and Hydrological Institute, Norrköping, Sweden.

Birkhead. A.L. and James, C.S. (2002) Muskingum river routing with dynamic bank storage. Journal of Hydrology 264, $113-132$. 
Chen, X. et al. (2007) A distributed monthly hydrological model for integerating spatial variations of basin topography and rainfall. Hydrological Processes 21, 42-252.

Fread, D. L. (1985) Applicability criteria for kinematic and diffusion routing models., Laboratory of Hydrology, National Weather Service, NOAA, US Dept. of Commerce, Silver Spring, Md.

Jayawardena, A.W. (1988) Stream flow simulations using Tank model: Application Hong Kong catchments. Hong Kong Engineering, Journal of the Hong Kong Institute of Engineering 16(7), 33-36.

Kohler, M.A. and Linsley, R. (1951) predicting the runoff from storm rainfall, In: National Oceanic and Atmospheric Administration Weather Bureau Research Papers, US Department of Commerce, Weather Bureau, Washington.

Koren, V. et al. ( 2003) Combining physically based and conceptual approaches in the development and parameterization of a distributed system, Information from Weather Radar and Distributed Hydrological Modelling (Proceedings of symposium HS03 held during IUGG2003 at Sapporo, Japan), 282. 101-108.

Liggett, J.A. and Cunge, J.A. (1975) Numerical methods of solution of the unsteady flow equations. In K. Mahmood and V. Yevjevich, eds. Unsteady Flow in Open Channels, Water Resources Publ., 89-182.

Linsley, R., Kohler, A. and Paulhus, J. L.H. (1986) Hydrology for Engineers. McGraw-Hill, New York.

Liu, Z., Martina, M.L. and Todini, E. (2005) Flood forecasting using a fully distributed model: application of the TOPKAPI model to the Upper Xixian Catchment, Hydrology and Earth System Sciences, 9(4). 347-364.

Maidment, D.R. and Fread, D.L. (1993) Handbook of Hydrology, Chap. 10, Flow Routing. ISBN 0070397325/9780070397323, McGraw-Hill.

McCarthy, G.T. (1938) The unit hydrograph and flood routing, Conference of North Atlantic Division, US Army Corps of Engineers, New London, CT. US Engineering.

Perumal, M. and Sahoo, B. (2008) Volume conservation controversy of the variable parameter Muskingum-Cunge method, Journal of Hydraulic Engineering 134(4), 475-483.

Ponce, V.M. and Chaganti, P.V. (1994) Variable parameter Muskingum-Cunge method. Journal of Hydrology 162(3-4), 433439.

Ponce, V.M. and Theurer, F.D. (1982) Accuracy criteria in diffusion routing. J. of Hydraulics Div., ASCE, 1C8(HY6), 747757.

Ponce, V.M. and Yevjevich, V. (1978) Muskingum Cunge method with variable parameters. Journal of Hydraulics Div., ASCE, 104(HY12), 1663-1667.

Robinson, J.S. and Sivapalan, M. (1995) Catchment-scale runoff generation model by aggregation and similarity analysis. In: Kalma, J.D. and Sivapalan, M. (eds) Scale Issues in Hydrological Modeling. Wiley, New York. 311-330.

Sittner, W.T, Schauss. C.E., and Monro, J.C. (1969) Continuous hydrograph synthesis with an API-type hydrologic model. Water Resources Research 5.1007-1022.

Smith, R.E. et al. (1995) KINEROS - A Kinematic Runoff and EROSionModel. In: Singh VP (ed) Computer models of watershed hydrology. Water Resources Publications, Highlands Ranch. 697-732.

Sugawara, M. (1979) Automatic calibration of the tank model , Hydrological Sciences Journal 24, 375-388.

Sugawara, M. (1995) Tank model, in V.P. Singh, (ed.) Computer Models of Watershed Hydrology. Water Resources Publications, Littleton, Colorado, USA.

Sugawara, M. et al. (1984) Tank model with snow component. Research Notes, No. 65, National Research Center for Disaster Prevention, Japan.

Tang, X., Knight, D. W. and Samuels, P. G. (1999) Volume conservation in variable parameter Muskingum-Cunge method. J. Hydraulic Eng. (ASCE) 125(6). 610-620.

Todini, E. and Ciarapica, L. (2001) The TOPKAPI model. In: Singh VP (ed) Mathematical models of large watershed hydrology, Chapter 12. Water Resources Publications, Highlands Ranch.

Todini, E. (1996) The ARNO rainfall-runoff model. J. Hydrol. 175, 339-382.

Wei, FQ., Hu, K.H. and Chen, J.( 2005) Determination of effective antecedent rainfall for debris flow forecast. Journal of Mountain Research 23. 4453-4457 (in Chinese).

Yao,C. et al. (2009) Application of developed Grid-Xinanjiang model to Chinese watersheds for flood forecasting purpose. J. Hydrol. Eng. doi: 10.1061/(ASCE) HE. 1943-5584.0000067

Zhang, Q. and Werner, A. (2009) Integrated surface-subsurface modeling of Fuxianhu Lake catchment, southwest China. Water Resource Manage 23, 2189-2204. doi:10.1007/s11269-008-9377-y

Zhao, Rj. (1992), The Xinanjiang model applied in China. J. Hydrol. 135, 371-381

Zhao, Rj. et al. (1980) The Xinanjiang model. In: Hydrological Forecasting (Proceedings Oxford Symposium). IAHS 129, 351-356.

Zhao, Y. et al. (2011) Discussion on using sntecedent precipitation index to supplement relative soil moisture data series. Procedia Environmental Sciences (B) 10, 1489-1495. 